\title{
OPTIMASI JARAK PENJEMPUTAN PENUMPANG CV. EIRA SAUDARA MENGGUNAKAN METODE PARTICLE SWARM OPTIMIZATION Studi Kasus : Travel Taxi Tiga Saudara Pontianak Kalbar
}

\author{
Dessy Natalia, Yundari, Yudhi \\ INTISARI
}

Traveling Salesman Problem (TSP) adalah suatu masalah optimasi untuk menentukan rute optimal perjalanan salesman yang melalui semua kota tujuan tepat satu kali dan kembali ke kota awal. Penyelesaian untuk masalah TSP ini mengharuskan penghitungan terhadap semua kemungkinan rute yang dapat diperoleh, kemudian memilih salah satu rute yang terpendek. Jika terdapat n kota yang harus dikunjungi, maka diperlukan proses pencarian sebanyak $(n-1)$ ! rute. Penelitian ini, bertujuan untuk mendapatkan penyelesaian rute terpendek penjemputan penumpang CV. Eira Saudara dengan metode Particle Swarm Optimization (PSO). PSO adalah teknik optimasi berbasis populasi, yang terinspirasi oleh tingkah laku sosial pada kawanan burung yang terbang berduyun-duyun (bird flocking) dan gerombolan ikan yang berenang berkelompok (fish schooling). Pada penelitian ini digunakan metode PSO dengan 8 titik lokasi penjemputan penumpang, dimana Jl. Tanjung Pura No.214 sebagai titik awal serta Bandar Udara Internasional Pontianak sebagai titik tujuan. Jarak penjemputan penumpang yang diperoleh adalah sejauh $59,2 \mathrm{~km}$ dengan kriteria pemberhentian $\left|F_{t}-F_{t-1}\right|<\varepsilon$, dimana nilai $\varepsilon=10^{-15}$.

Kata kunci : Traveling Salesman Problem, Particle Swarm Optimization, fitness, rute penumpang.

\section{PENDAHULUAN}

Transportasi angkutan darat yang berupa taksi lebih dikenal masyarakat di Kalimantan Barat dengan sebutan travel. Travel memiliki sistem layanan penjemputan dan pengantaran penumpang sampai ke tempat tujuan. Hal ini menjadikan travel sebagai jenis alat transportasi pilihan konsumen yang hendak melakukan perjalanan dalam/luar kota dan antar-jemput airport. Penyedia jasa travel harus memperhatikan kualitas pelayanan dan keamanan penumpang. Pelayanan yang memuaskan akan menjadi daya tarik tersendiri bagi konsumen terhadap jasa pelayanan travel.

CV. Eira Saudara merupakan salah satu penyedia jasa travel. Seorang sopir taksi diharuskan menjemput setiap penumpang tepat satu kali dan berakhir pada lokasi awal dimana seorang sopir memulai perjalanan. Maksimal penumpang yang dijemput untuk satu taksi adalah tujuh orang penumpang. Sopir harus bisa menentukan rute penjemputan penumpang secara tepat agar target yang harus dicapai penyedia layanan jasa travel sesuai dengan yang diharapkan.

Permasalahan seorang sopir Taxi Tiga Saudara yang harus menjemput penumpang dengan jarak terpendek termasuk ke dalam permasalahan Traveling Salesman Problem (TSP). Salesman tersebut mempunyai masalah dalam hal menentukan lokasi mana yang lebih dulu dikunjungi sedemikian sehingga total jarak dan setiap lokasi hanya boleh dilalui sekali dalam satu perjalanan. TSP dikenal sebagai permasalahan yang bersifat kombinatorial. TSP dapat digambarkan dalam bentuk Cycle[1]. Cycle adalah jalur yang mulai dari suatu simpul dan berakhir pada simpul yang sama[2].

Permasalahan TSP dapat diselesaikan menggunakan metode Particle Swarm Optimization (PSO). PSO adalah teknik optimasi berbasis populasi terinspirasi dari perilaku sosial binatang membentuk formasi tertentu [3]. Optimasi merupakan suatu upaya sistematis untuk mencari nilai minimum atau maksimum dari suatu fungsi tujuan dengan tetap memperhatikan pembatas yang ada [4]. Fungsi tujuan digunakan untuk mencari jarak terpendek penjemputan penumpang oleh seorang sopir travel Taxi Tiga Saudara di CV. Eira Saudara dengan metode PSO. 


\section{MASALAH TRAVELLING SALESMAN PROBLEM (TSP)}

TSP merupakan permasalahan seorang salesman harus mengunjungi semua kota tujuan tepat satu kali dan harus kembali ke kota awal. Penentuan jarak yang optimal merupakan tujuan utama pada TSP. Fungsi tujuan dari masalah TSP adalah sebagai berikut [5] :

$$
\min f(x)=\sum_{i=1}^{n} \sum_{j=1}^{n} c_{i j} x_{i j}
$$

Fungsi batasannya adalah:

$$
\begin{gathered}
\sum_{j=1}^{n} x_{i j}=1, \quad i=1, \ldots \ldots, n, \\
\sum_{\substack{i=1 \\
n}}^{n} x_{i j}=1, \quad j=1, \ldots \ldots, n, \\
x_{i j} \in\{0,1\}, \quad i, j=1,2, \ldots \ldots \ldots \ldots n
\end{gathered}
$$

dengan $c_{i j}$ adalah jarak dari kota-i ke kota-j, dengan i adalah kota awal, j adalah kota tujuan dan $x_{i j}$ bernilai 1 jika $i j$ masuk dalam rute dan 0 jika $i j$ tidak merupakan bagian dari rute. Dari fungsi tujuan permasalahan TSP selanjutnya mencari rute dan jarak terpendek perjalanan seorang salesman menggunakan metode PSO.

\section{METODE PARTICLE SWARM OPTIMIZATION (PSO)}

PSO adalah teknik optimasi berbasis populasi, yang terinspirasi oleh tingkah laku sosial pada kawanan burung yang terbang berduyun-duyun (bird flocking) dan gerombolan ikan yang berenang berkelompok (fish schooling)[3]. PSO memiliki memory untuk menyimpan solusi terbaik. Setiap partikel pada PSO tidak pernah mati, posisi dan kecepatan terbang partikel di-update pada setiap iterasi sehingga partikel tersebut bisa menghasilkan solusi baru yang lebih baik. Solusi-solusi (partikel) yang potensial, "terbang" dalam ruang masalah mengikuti partikel-partikel yang optimum saat ini (current optimum particles). Dengan konsep ini, PSO lebih mudah diimplementasikan dan parameter yang harus diatur hanya sedikit[6]. Ada beberapa teori yang berusaha menjelaskan mengenai tingkah laku kawanan hewan tersebut. Perilaku sosial tingkah laku kawanan hewan mengikuti tiga aturan berikut[7]:

a. Separation : setiap individu akan berusaha untuk saling menjauh jika merasa terlalu dekat dengan individu di sebelahnya.

b. Aligment : setiap individu memiliki kecendrungan untuk bergerak kearah individu di sebelahnya.

c. Cohesion : setiap individu berusaha untuk bergerak ditengah-tengah individu tetangganya.

Ilustrasi cara kerja, diambil $N$ sejumlah partikel (di dalam PSO, individu sering disebut dengan partikel) yang bergerak bersama-sama disuatu ruang pencarian $S$. Setiap partikel $i$ adalah kandidat penyelesaian dan dinyatakan dengan vektor $x_{i}$. Setiap partikel memiliki posisi, kecepatan dan akan bergerak berdasarkan pengalaman, informasi dari lingkungan sosialnya dan posisi terkini dari partikel tersebut. Pengalaman partikel $i$ dinyatakan oleh posisi terbaik $p_{i}$, yang pernah dicapai oleh partikel tersebut. Informasi dari lingkungan diwakili oleh partikel yang memiliki posisi terbaik $g$, di dalam kumpulan partikel tersebut. Sedangkan posisi partikel $i$ saat ini dinyatakan dengan $x_{i}^{t-1}$ [3]. Secara matematis perubahan kecepatan (velocity) pada metode ini direpresentasikan dengan Persamaan (2)[8]

$$
v_{i}^{t}=w v_{i}^{t-1}+\varphi C_{1}\left(p_{i}-x_{i}^{t-1}\right)+\varphi C_{2}\left(g-x_{i}^{t-1}\right)
$$

dengan

$v_{i}^{t} \quad=$ Kecepatan partikel ke- $i$ pada iterasi ke- $t$; 
$\varphi=$ Vektor random dengan rentang nilai $[0,1] ;$

$C_{1} \quad=$ Koefisien 'cognitive learning' (kecerdasan individu);

$C_{2} \quad=$ Koefisien 'social learning' (hubungan sosial antar individu);

$p_{i} \quad=P_{\text {best }}$ (posisi partikel terbaik) ke- $i$;

$g \quad=$ Nilai $P_{\text {best }}$ terbaik dari semua partikel;

$x_{i}^{t-1}=$ Posisi partikel ke- $i$ pada iterasi ke- $(t-1)$;

$w \quad=$ Koefisien inersia.

Koefisien inersia $w$ dipakai untuk menghitung kecepatan partikel. Nilai $w$ yang besar bagus dalam eksplorasi ruang pencarian sementara nilai $w$ yang kecil bagus untuk intensifikasi. Pada setiap iterasi nilai fungsi inersia di-update melalui Persamaan (3)[4]:

$$
w_{t}=w_{\max }-\frac{t}{t_{\max }}\left(w_{\max }-w_{\min }\right),
$$

dengan;

$w_{\max }=$ Inersia maksimum $(0,9)$;

$w_{\text {min }}=$ Inersia minimum $(0,4)$;

$t \quad=$ Iterasi sekarang;

$t_{\max }=$ Jumlah maksimum iterasi.

Seiring dengan berubahnya kecepatan, maka terjadi perubahan pada posisi partikel di setiap iterasi yang dapat dihitung dengan Persamaan (4)

$$
x_{i}^{t}=x_{i}^{t-1}+v_{i}^{t} .
$$

Fungsi fitness digunakan untuk mengukur tingkat kebaikan atau kesesuaian (fitness) suatu solusi dengan solusi yang dicari. Fungsi fitness bisa berhubungan langsung dengan fungsi tujuan atau bisa juga sedikit modifikasi terhadap fungsi tujuan. Sejumlah solusi yang dibangkitkan dalam populasi akan dievaluasi menggunakan fungsi fitness. Pada kasus optimasi, dikenal dengan dua masalah yaitu maksimasi dan minimasi. Penentuan nilai fitness $(F)$ dapat dihitung dengan Persamaan (5)[1] :

dengan

$$
F=\frac{1}{f(x)} \text {. }
$$

$f(x)=$ Jumlah total jarak partikel;

$x \quad=$ Partikel.

\section{Metodologi Penelitian}

Pada proses alur penjemputan penumpang Taxi Tiga Saudara oleh seorang sopir taksi dengan cara mengetahui semua alamat penumpang taksi yang akan berangkat ke Bandar Udara Internasional Pontianak. Penentuan rute terpendek penjemputan penumpang diawali dengan input data matriks jarak yang telah didapat menggunakan Google Maps. Inisialisasi parameter permasalahan terdiri dari dimensi permasalahan jumlah partikel $(n p)$, jumlah kota $(n k)$, nilai konstanta random $\left(C_{1}, C_{2}\right)$, koefisien inersia $(w)$, ruang pencarian (search space) yang dinyatakan oleh batas atas $(b a)$ dan batas bawah $(b b)$. Membentuk posisi dan kecepatan awal, selanjutnya menghitung total jarak dan nilai fitness. Perhitungan total jarak dan nilai fitness digunakan untuk dapat memperoleh nilai Pbest dari masing-masing partikel yang ada. Kemudian dari hasil Pbest yang diperoleh masing-masing partikel, nilai Pbest terkecil menjadi nilai Gbest disetiap kali proses iterasi dilakukan. Proses selanjutnya adalah update kecepatan partikel dan update posisi partikel. Dari proses tersebut menghasilkan partikel baru, dimana dengan nilai rata-rata fitness tertinggi menjadi solusi rute dengan jarak terpendek yang merupakan solusi mendekati optimum. 


\section{Pengujian Jumlah Partikel}

Pada pengujian jumlah partikel bertujuan untuk mengetahui pengaruh ukuran partikel pada masing-masing nilai fitness yang diperoleh oleh sistem[9]. Hasil pengujian rata-rata nilai fitness berdasarkan jumlah partikel, dengan ukuran iterasi 100 dan jumlah titik lokasi 8 dapat dilihat pada Gambar 2 sebagai berikut :

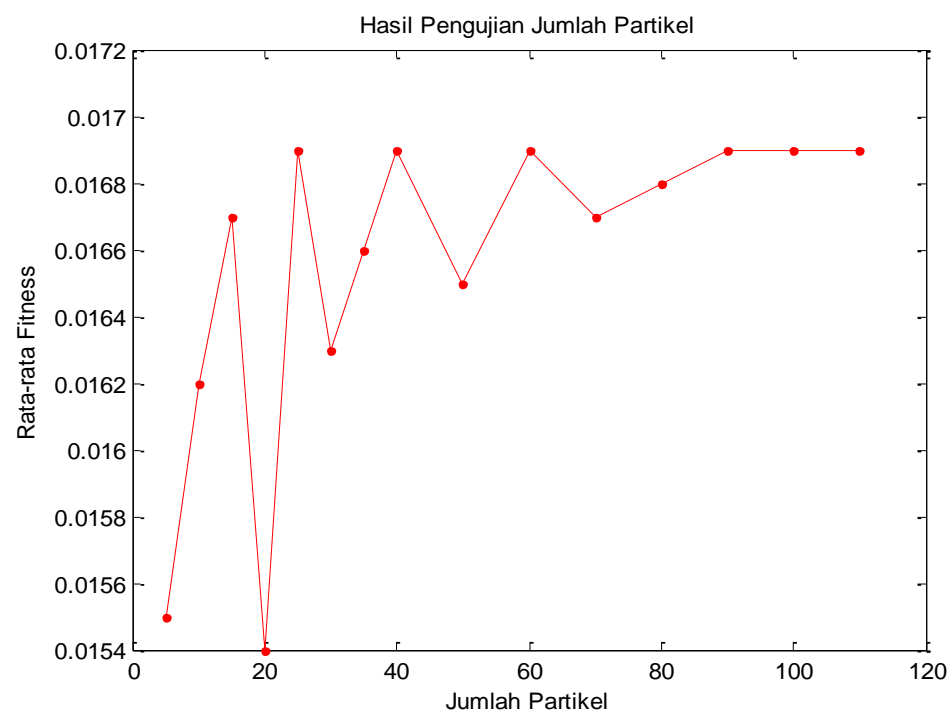

Gambar 2 Grafik Pengujian Jumlah Partikel

Berdasarkan grafik hasil pengujian pada Gambar 2 menunjukkan bahwa rata-rata nilai fitness tertinggi yaitu 0,0169 pada jumlah partikel 90 dan rata-rata nilai fitness terendah sebesar 0,0154 pada jumlah partikel 20. Dari pengujian grafik rata-rata nilai fitness adanya peningkatan dan penurunan pada jumlah partikel yang diajukan. Terlihat pada ukuran partikel 5 sampai 60 mengalami peningkatan dan penurunan, pada partikel 70 sampai 110 mengalami peningkatan.

\section{HASIL DAN PEMBAHASAN}

Berdasarkan wawancara langsung dengan salah satu pemilik taksi di CV. Eira Saudara, alur penjemputan penumpang di mulai dari Jl.Tanjungpura 214 selanjutnya seorang sopir menjemput penumpang ke setiap alamat yang telah diberikan calon penumpang taksi. Kendaraan yang di pakai oleh penyedia jasa travel ini yaitu jenis mobil dan lebih dikenal dengan sebutan Taxi Tiga Saudara. Jumlah penumpang Taxi Tiga Saudara maksimal 7 orang. Data penumpang diperoleh dari aplikasi penentuan lokasi yang terdapat pada android khususnya penjemputan penumpang di daerah kota Pontianak. Penumpang taksi adalah sekelompok orang yang akan berangkat ke Bandar Udara Internasional Supadio. Asumsi TSP dalam permasalahan penjemputan penumpang adalah :

a Setiap lokasi penumpang hanya dikunjungi satu kali dan lokasi penumpang diasumsikan sebagai titik.

b Jalan yang dilalui tidak ada yang satu arah, maka jarak antar titik adalah simetris, artinya jarak dari titik A ke B sama dengan jarak dari titik B ke A.

c Jarak antar titik harus jarak yang paling dekat, pencarian jarak tersebut menggunakan maps yang terdapat pada android.

d Seorang supir taksi harus kembali lagi kepangkalan.

Sebagai contoh diberikan alamat penumpang Taxi Tiga Saudara yang merupakan titik penjemputan (Tabel 1). 
Tabel 1. Alamat Penumpang Taxi Tiga Saudara

\begin{tabular}{cl}
\hline Titik & \multicolumn{1}{c}{ Alamat Penumpang } \\
\hline 1 & Jl. Tanjung Pura No.214 (depan Yamaha Sentral samping SPBU). \\
2 & Khatulistiwa Hotel, Jl.Dipenogoro \\
3 & Jl.Alianyang No.62 \\
4 & Gg.Apel 4 No.5,Sungai Jawi Luar, Pontianak \\
5 & Permata Khatulistiwa,Jl.Sungai Raya Dalam, No.01 \\
6 & Kom. Mega Mas, Jl.Parit H.Mukhsin, No.B.09 \\
7 & Jl.Purnama, Gg.Purnama Agung, No.A23 \\
8 & Bandar Udara Internasional Pontianak \\
\hline
\end{tabular}

Selanjutkan disajikan lokasi geografis dalam peta penumpang Taxi Tiga Saudara pada Gambar 3. Lokasi penumpang tersebar di kota Pontianak, provinsi Kalimantan Barat.

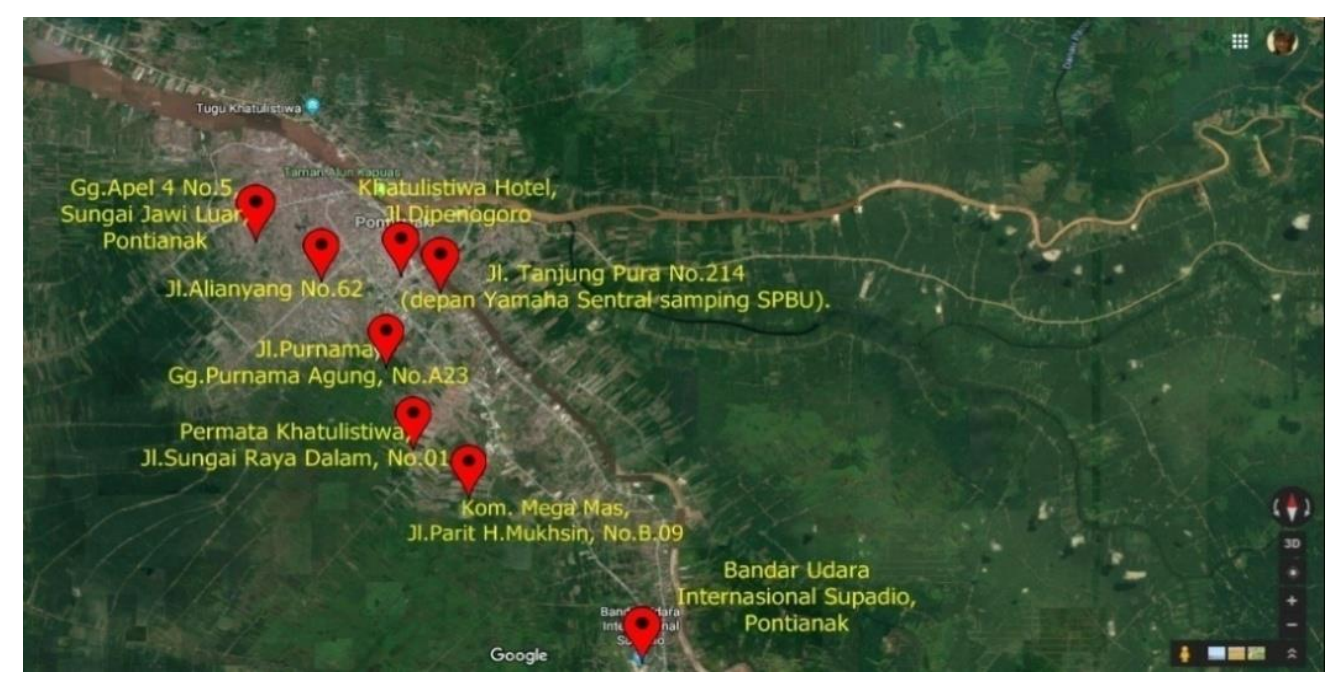

Sumber: Google Maps

Gambar 3 Lokasi penumpang

Kemudian, diperoleh tabel jarak kantor Taxi Tiga Saudara ke lokasi penumpang dan jarak antar lokasi penumpang oleh salah seorang sopir Taxi Tiga Saudara yang disajikan pada Tabel 2.

Tabel 2. Jarak Kantor Taxi Tiga Saudara ke Lokasi Penumpang dan Antar Lokasi Penumpang (dalam satuan km)

\begin{tabular}{|c|c|c|c|c|c|c|c|c|}
\hline$c_{i j}$ & 1 & 2 & 3 & 4 & 5 & 6 & 7 & 8 \\
\hline 1 & 0 & 2,7 & 4,8 & 5,3 & 6,7 & 11,3 & 6,3 & 18 \\
\hline 2 & 2,7 & 0 & 2,5 & 3,6 & 7,8 & 8,9 & 4,4 & 18 \\
\hline 3 & 4,8 & 2,5 & 0 & 3,7 & 8,6 & 11 & 3,5 & 19 \\
\hline 4 & 5,3 & 3,6 & 3,7 & 0 & 11,1 & 13 & 5,6 & 20 \\
\hline 5 & 6,7 & 7,8 & 8,6 & 11,1 & 0 & 6 & 6,7 & 14 \\
\hline 6 & 11,3 & 8,9 & 11 & 13 & 6 & 0 & 7,8 & 15 \\
\hline 7 & 6,3 & 4,4 & 3,5 & 5,6 & 6,7 & 7,8 & 0 & 19 \\
\hline 8 & 18 & 18 & 19 & 20 & 14 & 15 & 19 & 0 \\
\hline
\end{tabular}

Sumber: Jarak yang terdapat pada Google Maps 


\section{PENERAPAN METODE PARTICLE SWARM OPTIMIZATION PADA MASALAH TRA VELLING SALESMEN PROBLEM}

PSO adalah teknik optimasi berdasarkan populasi yang terinspirasi oleh prilaku sosial kawanan burung atau kawanan ikan. Dengan kata lain, optimasi merupakan proses mencari nilai terbaik berdasarkan fungsi tujuan. PSO merupakan salah satu metode untuk menyelesaikan masalah TSP. Urutan langkah-langkah yang digunakan untuk menyelesaikan masalah TSP menggunakan PSO adalah sebagai berikut :

\section{Input parameter}

Jumlah partikel dalam swarm $(\mathrm{np})=90$, batas nilai koefisen random ba $=1, \mathrm{bb}=0, w_{\max }=0,9$ $w_{\text {min }}=0,4$, kriteria pemberhentian $\left|F_{t}-F_{t-1}\right|<\varepsilon$, dengan $F_{t}$ adalah nilai fitness saat $t$.

Posisi dan Kecepatan awal

Pembangkitan bilangan real $(0,1)$ secara acak sejumlah titik lokasi penumpang CV. Eira Saudara yang akan dituju (jumlah kolom) dan sejumlah partikel (jumlah baris) baik untuk posisi $\left(x_{i}^{t}\right)$ maupun kecepatan $\left(v_{i}^{t}\right)$ dengan $i=(1,2,3,4, \ldots ., 90)$ pada $t=1$. Jika titik awal diasumsikan 1 dan 8 adalah titik tujuan, maka perhitungan untuk 90 partikel diperoleh posisi awal :

Tabel 3. Posisi Awal $\left(x_{i}^{t}\right)$ dengan 6 Titik Lokasi

\begin{tabular}{|c|c|c|c|c|c|c|}
\hline & 2 & 3 & 4 & 5 & 6 & 7 \\
\hline$x_{1}^{1}$ & 0,6896 & 0,6359 & 0,3798 & 0,0228 & 0,7896 & 0,4766 \\
\hline$x_{2}^{1}$ & 0,1318 & 0,7984 & 0,9797 & 0,4241 & 0,7992 & 0,9119 \\
\hline$\vdots$ & $\vdots$ & $\vdots$ & $\vdots$ & $\vdots$ & $\vdots$ & $\vdots$ \\
\hline$x_{80}^{1}$ & 0,2554 & 0,8397 & 0,5677 & 0,9721 & 0,9912 & 0,8750 \\
\hline$x_{81}^{1}$ & 0,5332 & 0,3717 & 0,8879 & 0,0315 & 0,5239 & 0,3486 \\
\hline$\vdots$ & $\vdots$ & $\vdots$ & $\vdots$ & $\vdots$ & $\vdots$ & $\vdots$ \\
\hline$x_{90}^{1}$ & 0,2033 & 0,4372 & 0,2607 & 0,6014 & 0,3796 & 0,5714 \\
\hline
\end{tabular}

Tabel 4. Kecepatan Awal $\left(v_{i}^{t}\right)$ dengan 6 Titik Lokasi

\begin{tabular}{|c|c|c|c|c|c|c|}
\hline & 2 & 3 & 4 & 5 & 6 & 7 \\
\hline$v_{1}^{1}$ & 0,6287 & 0,1599 & 0,5643 & 0,9933 & 0,3008 & 0,1986 \\
\hline$v_{2}^{1}$ & 0,8778 & 0,6668 & 0,1874 & 0,3567 & 0,7981 & 0,6725 \\
\hline$\vdots$ & $\vdots$ & $\vdots$ & $\vdots$ & $\vdots$ & $\vdots$ & $\vdots$ \\
\hline$v_{80}^{1}$ & 0,6086 & 0,6853 & 0,0478 & 0,5164 & 0,8171 & 0,9761 \\
\hline$v_{81}^{1}$ & 0,2197 & 0,6203 & 0,7383 & 0,0075 & 0,5317 & 0,2782 \\
\hline$\vdots$ & $\vdots$ & $\vdots$ & $\vdots$ & $\vdots$ & $\vdots$ & $\vdots$ \\
\hline$v_{90}^{1}$ & 0,2033 & 0,2607 & 0,3796 & 0,4372 & 0,5714 & 0,6014 \\
\hline
\end{tabular}

Berdasarkan Tabel 3 masing-masing partikel diurutkan dari kecil ke besar, maka akan diperoleh rute dan jarak yang dibentuk dari posisi awal bilangan random yang terurut lihat pada Tabel $5 x_{i}^{t^{*}}$ adalah:

Tabel 5. Rute Awal Setelah diurutkan

\begin{tabular}{|c|c|c|c|c|c|c|c|c|c|c|}
\hline & \multicolumn{9}{|c|}{ Rute } & $f(x)$ \\
\hline$x_{1}^{1^{*}}$ & 1 & 5 & 4 & 7 & 3 & 2 & 6 & 8 & 1 & 71,3 \\
\hline$x_{2}^{1^{*}}$ & 1 & 2 & 5 & 3 & 6 & 7 & 4 & 8 & 1 & 81,5 \\
\hline$\vdots$ & $\vdots$ & $\vdots$ & $\vdots$ & $\vdots$ & $\vdots$ & $\vdots$ & $\vdots$ & $\vdots$ & $\vdots$ & $\vdots$ \\
\hline$x_{80}^{1^{*}}$ & 1 & 2 & 4 & 3 & 7 & 5 & 6 & 8 & 1 & 59,2 \\
\hline$x_{81}^{1^{*}}$ & 1 & 5 & 7 & 3 & 6 & 2 & 4 & 8 & 1 & 78,4 \\
\hline$\vdots$ & $\vdots$ & $\vdots$ & $\vdots$ & $\vdots$ & $\vdots$ & $\vdots$ & $\vdots$ & $\vdots$ & $\vdots$ & $\vdots$ \\
\hline$x_{90}^{1^{*}}$ & 1 & 2 & 4 & 6 & 3 & 7 & 5 & 8 & 1 & 72,5 \\
\hline
\end{tabular}


Sebagai ilustrasi Tabel 3, lihat baris pertama, posisi pada partikel pertama iterasi pertama $x_{1}^{1}$ setelah diurutkan dari terkecil sampai terbesar diperoleh baris $x_{1}^{1^{*}}$ pada tabel 5 yaitu:

$$
\{0,0228 ; 0,3798 ; 0,4766 ; 0,6359 ; 0,6896 ; 0,7896\} \text {. }
$$

Dari urutan bilangan random ini menghasilkan rute 1-5-4-7-3-2-6-8-1. Sebelum diurutkan 0,0228 terdapat pada posisi ke 5, 0,3798 terdapat pada posisi ke 4, demikian seterusnya. Partikel yang lain dilakukan cara yang sama untuk mendapatkan rute. Berdasarkan Tabel 5 diperoleh jarak minimum $(f(x))$ yaitu 59,2 km pada partikel ke $x_{80}^{1}$ dengan Gbest $=x_{80}^{1}$. Selanjutnya dari nilai Gbest tersebut dicari kecepatan untuk iterasi ke-2 dengan Persamaan (2) sehingga diperoleh:

$$
\begin{aligned}
& v_{1}^{2}=0,8[0,6287 \quad 0,1599 \quad 0,5643 \quad 0,9933 \quad 0,3008 \quad 0,1986] \\
& +0,6\left(\left[\begin{array}{llllll}
0,6896 & 0,6359 & 0,3798 & 0,0228 & 0,7896 & 0,4766
\end{array}\right]\right. \\
& \text { - } \left.\left[\begin{array}{llllll}
0,6896 & 0,6359 & 0,3798 & 0,0228 & 0,7896 & 0,4766
\end{array}\right]\right) \\
& +0,3\left(\left[\begin{array}{llllll}
0,2554 & 0,8397 & 0,5677 & 0,9721 & 0,9912 & 0,8750
\end{array}\right]\right. \\
& \text { - } \left.\left[\begin{array}{llllll}
0,6896 & 0,6359 & 0,3798 & 0,0228 & 0,7896 & 0,4766
\end{array}\right]\right) \\
& v_{1}^{2}=\left[\begin{array}{llllll}
0,3727 & 0,18906 & 0,500781 & 1,07943 & 0,30112 & 0,2784
\end{array}\right] .
\end{aligned}
$$

Kemudian untuk partikel ke 1 update posisi dengan Persamaan (4) dan diperoleh posisi partikel ke-1 pada iterasi ke-2 yaitu:

$$
\begin{aligned}
x_{1}^{2} & =\left[\begin{array}{llllll}
0,6896 & 0,6359 & 0,3798 & 0,0228 & 0,7896 & 0,4766
\end{array}\right] \\
+\left[\begin{array}{llllll}
0,3727 & 0,18906 & 0,500781 & 1,07943 & 0,30112 & 0,2784
\end{array}\right] & \begin{array}{rlllll}
1,0623 & 0,82496 & 0,88761 & 1,10223 & 1,09072 & 0,755
\end{array} .
\end{aligned}
$$

Hal ini dilakukan untuk semua partikel, setelah itu diulangi lagi langkah mengevaluasi setiap rute yang dihasilkan setiap partikel, memilih Pbest, Gbest, update posisi, kecepatan dan seterusnya sampai kriteria terpenuhi $\left|F_{t}-F_{t-1}\right|<\varepsilon$. Jarak yang diperoleh adalah 59,2 km dengan jumlah partikel 90.

\section{KESIMPULAN}

Berdasarkan pembahasan mengenai algoritma Particle Swarm Optimization dan apikasinya pada masalah TSP, dalam kasus penjemputan penumpang Taxi Tiga Saudara oleh seorang sopir taksi diperoleh jarak terpendek yang optimal. Rute terpendek penjemputan penumpang oleh seorang sopir travel Taxi Tiga Saudara adalah dari Jl. Tanjungpura No.214 - Khatulistiwa Hotel, Jl.Dipenogoro Gg.Apel 4 No.5, Sungai Jawi Luar, Pontianak - Jl.Alianyang No.62 - Jl.Purnama, Gg.Purnama Agung, No.A23 - Permata Khatulistiwa, Jl.Sungai Raya Dalam, No.01 - Kom. Mega Mas, Jl.Parit H.Mukhsin, No.B.09 - Bandar Udara Internasional Pontianak - Jl. Tanjung Pura No.214. Rute yang diperoleh adalah 1-2-4-3-7-5-6-8-1 dengan total jarak 59,2 km.

\section{DAFTAR PUSTAKA}

[1] Yan X, Zhang C \& Liu H, Solve Travelling Salesman Problem Using Particle Swarm Optimization Algorithm. IJCSI International Journal of Computer Science Issue, 2012; Vol 9: 264-271.

[2] Siang JJ, Matematika Diskrit dan Aplikasinya pada Ilmu Komputer. Yogjakarta: Andi, 2006.

[3] Kennedy J \& Eberhart R, Particle Swarm Optimization. IEEE International Conference on Neural Network, 1995; 1942-1948.

[4] Purnomo HD, Cara Mudah Belajar Metode Optimasi Metaheuristik Menggunakan Matlab. Yogyakarta: Gava Media, 2014.

[5] Santoso B, Pengantar Metaheuristik. Surabaya: ITS Tekno Sains, 2017.

[6] Suyanto, Algoritma Optimasi Deterministik atau Probabilitik. Yogyakarta: Graha Ilmu, 2014.

[7] Reynolds CW, Flocks, Herds and Schools: A Distributed Behavioral Model. ACM SIGGRAPH Computer Graphics, 1987; Vol 21: 25-34. 
[8] Shi Y \& Eberhart R, A Modified Particle Swarm Optimization. IEEE International Conference on Evolutionary Computation, 1998; 69-73.

[9] Putri RN Widodo AW \& Cholissodin I, Optimasi Multiple Travelling Salesman Problem Pada Pendistribusian Air Minum Menggunakan Algoritma Particle Swarm Optimization. Jurnal Pengembangan Teknologi Informasi Dan Ilmu Komputer, e-ISSN: 2548-964x, 2017; Vol 1: 842-847.

$\begin{array}{ll}\text { DESSY NATALIA } & \begin{array}{l}\text { Jurusan Matematika FMIPA UNTAN, Pontianak } \\ \text { dessynatalia2012@gmail.com }\end{array} \\ \text { YUNDARI } & \text { Jurusan Matematika FMIPA UNTAN, Pontianak } \\ & \text { yundari@ math.untan.ac.id } \\ \text { Y Jurusan Matematika FMIPA UNTAN, Pontianak } \\ \text { Yhye_dhoank@yahoo.co.uk }\end{array}$

